\title{
Ethnic Media and Identity Construction: The Representation of Women in the An Ethnic Newspaper in South Africa
}

\author{
D. Soobben \\ Lecturer: Department Media, Languages \& Communication \\ Faculty of Arts, Durban University of Technology \\ Tel: +27 (0) 31-3736617, e-mail: soobbend@dut.ac.za \\ V.P. Rawjee \\ Snr. Lecturer and HOD: Department of Public Relations Management \\ Faculty of Management Sciences Durban University of Technology \\ Tel: +27 (0) 31-3736826, e-mail: rawjeeve@dut.ac.za
}

\section{Doi:10.5901/ajis.2013.v2n8p697}

\begin{abstract}
Media are powerful agents of socialisation. Through representation, media helps in constructing and reproducing gender identities. The representation of how women are constructed by the media has travelled due to globalization. The $2006 \mathrm{Global}$ Media Monitoring Project reveals that women are under-represented in news. The media are therefore construed as constructing gender subjectivity. For example, women are literally absent in news, politics and economics and hardly ever appear as spokespersons or as field experts. These subjective representations are often framed though the lenses of the media producers and are influenced by the political economy of the media. Media are therefore seen as representing a distorted version of women. Gallagher (2004), however states that in South Africa, the process of changing gender in the newsroom has started and media audiences, texts and institutions have changed, largely due to the persistent gender advocacy. Based on this, this paper sets out to investigate how Indian women are represented in a South African newspaper targeted at a cross-national ethnic readership. A qualitative methodology was used to analyse content and photographs appearing in ten consecutive publications of the newspaper. Themes emanating from the literature review were used to analyse newspaper content. The major findings of the investigation indicate that representations of the South African Indian woman has undoubtedly expanded, taking into account new roles and offering new identities, however certain stereotypical identities continue to prevail.
\end{abstract}

\section{Introduction: The media as an instrument for representation}

There are the many ways that humans use in classifying their own and other people's identity. Nationality, gender and ethnicity are some of the common streams of identity classification. Jeffres (2000) view of ethnicity is a result of actions not only by ethnic groups as they define themselves and their culture but also the result of external social, economic, and political processes. The concept of ethnic identity is of primordial importance for the understanding of what ethnic groups encounter in their position as minorities inside a dominant culture (Phinney, 1990). Social identity theory posits that people obtain positive reinforcement from a sense of belonging to a distinct group; particular memberships or social identities can be created on the basis of any commonly shared characteristics (Turner, 1999). The mass media counts as external factors that affect the constitution of an ethnicity and the perpetuation of a culture. The media therefore offer us ways to understand ethnicity and ethnic issues (O'Shaughnessy \& Stadler, 2006). The media are agents of socialisation, a carrier of culture, and a way of communicating ideology (O'Shaughnessy \& Stadler, 2006). The media are therefore seen as important vehicles in giving construction, images and representation of discourses around issues of ethnic identity.

Stuart Hall (1997) describes representation as an essential part of the process by which meaning is produced and exchanged between members of a culture. It involves the use of language, of signs and images which stand for or represent things. Hall's (1997) work has explored representation as a signifying practice in a rich diversity of social contexts and examines the way that media keep those who are powerful in society in control, while at the same time, keeping the powerless people powerless. The media also has the power to influence society by conveying stereotypical and patriarchal representations of women. Ashford and Clifton (2005) assert that although women constitute over fifty 
percent of the world's population, they are under-represented in the media. Holland (2004) maintains that men, who produce the pages, will continue to build their power on the decorative excess of the women who are pictures on them. Therefore, the way women are represented in the media influences the public's opinions and thoughts. Thus, it would be a mistake to overlook the potential that ethnic media texts have for providing insight about in-group dynamics, prevailing cultural messages, and social identification (Ricle Mayorga, 2007). Milestone and Meyer (2012) argue that representations matter: they are not 'only' words and images, but reflect and encourage certain ways of thinking about and acting in relation to women. Parry and Karam (2001) maintain that the media has always possessed the power to impart ideological and patriarchal messages. Other studies (Courtney and Lockeretz, 1971); Tuchman, 1978; and Williamson, 1978) show that women are often portrayed in domestic working roles, non-working activities, and women's images are used to sell products.

Through representation, the media has the ability to influence public opinion and perception. Subervi-Velez, (1993) therefore maintains that ethnic media, in particular provides the means for minority members to participate in the production of media messages, to create more accurate and favorable portrayals, and ultimately, to conceive and disseminate ethnic identities. However, whilst ethnic media can address integrations and pluralism there are at the same time many other functions that ethnic media may perform (Johnson, 2003). One such function is the representation of ethnic women in the media. Both general audience and ethnic media contribute to the adoption, elimination, and modification of values, attitudes, and beliefs within groups as well as between in-groups and out-groups (Renz, 2003). They are agents in the social processes of acculturation and/or pluralism and they influence both social and personal identities (Johnson, 2003). Social identities as well as personal identities are deeply influenced by mediated media messages, which create constant renegotiations of the values and beliefs that guide human interaction. The renegotiation of identity often lies in the changes brought about through deviant representations. These deviances bring about subtle changes and influences public opinion and identity construction. The media therefore has the power to represent women in diverse roles offering them new identity that deviates from the patriarchal stereotypical role. Milestone and Meyer's (2012) study shows that the representations of women have in fact undoubtedly diversified, taking into account new roles and offering new identities, but traditional images and norms continue to exist and exert powerful influence. Based on this this paper sets out to investigate how Indian women are represented in a South African ethnic newspaper targeted at a cross-national ethnic readership. It analyses the coverage of stories on women using content analysis of word, sentence (language) and visual imagery from the newspaper. Based on this, relational content analysis then determines the meanings resultant of gender stereotypes in the media.

\section{Ethnic media representation}

Although one of the first studies that examined the social-psychological effects of media exposure on racial/ethnic attitudes looked at film content (Peterson, Thurstone, Shuttlesworth, \& May, 1933), recent research (Brown \& Campbell, 1986; Coltrane \& Messineo, 2000; Entman, 1992, Mastro \& Greenberg, 2000; Thomas \& Treiber, 2000) based on racial media stereotyping has been conducted on various media sources such as news stories, television programs, music videos, and magazine advertisements. Findings from these studies show under-representation of racial minorities and that members of racial groups are often depicted in stereotypical ways. These studies show that racial stereotypes in the media have been known to influence racial attitudes and ethnic identities and also play role in identity formation. Exposure to stereotypical media content is stored as a general view about all members of the group that is being portrayed. Constant exposure to media messages according to Fourie (2004), can affect behaviour over a longer period of exposure to media content. This has relevance in the agenda setting theory which stipulates that the mass media has the ability to transfer items of prominence on the public agenda. This in turn directs thought processes and attention towards certain issues by the possible exclusion or scant coverage of certain items and an over focus on other issues. This means that the media will have an effect on public opinion and therefore shape opinions and beliefs about ethnic groups. Therefore central to the argument of representation of women is the construction of identity and that the media is important in shaping identity because they provide the "discursive fields through which meaning is produced in relation to power" (Woodward, 2002). In other words, the media creates the means for people to engage in media rituals that define their identity (Wasserman, 2008). South Africans in particular have additional complexities in terms of identity construction. During Apartheid media structures helped the Apartheid government to create economic classes and imposed racial and ethnic identities, they therefore contributed significantly to identity and ethnic formation (Wasserman, 2008).

Stereotypical media portrayal of ethnic groups is a cause for concern as audiences often interpret this as the norm 
and these representations therefore distort reality. In South Africa, Indian woman appear very rarely in main stream news. Stam and Spence (1983) argue that structuring absence is when the lack of images of people of color defines white peoples as the central/natural identity category. The tendency within Western culture has been for the media representations to be produced by whites and thus most epitomize a white view of the world and of other ethnic groups (O'Shaughnessy \& Stadler: 2006). Stam and Spence (1983) argue that the absence of representations 'is as bad as distorting stereotypes' and can be even more problematic than negative representations.

Milestone and Meyer (2012) cite an example where popular culture has a history of representing women as centrally concerned with and in need of love, romance and relationship. This is a misrepresentation of women. Therefore Stam and Spence (1983) further add that misrepresentation of ethnic groups is another important issue to consider, as is the issue of, who is accorded the right and the ability to make representations and who has access to the media.

Carter and Steiner (2004), however maintain that although many clearly gendered stereotypes still inform media content today, the rigidity of such hierarchical feminine gendered identity has nevertheless begun to break down. An increasingly varied array of feminine images and role models is now available, some of which offer progressive and sometimes challenging alternatives. Milestone and Meyer (2012), further reinforce this and maintain that representations of women have undoubtedly diversified, taking into account new roles and offering new identities, but traditional images and norms continue to exist and exert powerful influence. Even though the process is at its early stages, the change is painfully slow especially amongst minority women. Gallagher (2004), also states that in South Africa, the process of changing gender in the newsroom has started and media audiences, texts and institutions have changed, largely due to the persistent gender advocacy. Gallagher, (2004) further states that media and gender activists have begun to find ways of initiating awareness of 'gender blindness' amongst media production houses. An example of this is the way women are represented in the Sunday Times Extra (a weekly supplement in the Sunday Times - a national newspaper in South Africa). Based on this, this paper sets out to investigate how Indian women are represented in a South African newspaper - the Sunday Times Extra (a weekly supplement in the Sunday Times - a national newspaper targeted at a cross-national ethnic readership).

\section{South African ethnic media}

In the past, the South African media was under tremendous strain as society was polarized and unequal. The South African media had to contend with social, political and economic conditions in a country with disparaging proportions. Understandably, the subject of gender representations did not seem to be a priority in the media and ethnic women were particularly at a disadvantage. Since democratization in 1994, gender representation and the position of women in the media industry in the South African media has received considerable attention. Morna, (2010) reports that there has been a marginal improvement in the proportion of women sources in the news in the region from $17 \%$ in the 2003 Gender and Baseline Study (GMBS) to $19 \%$ in the 2010 Gender and Media Progress Study (GMPS). There have also been concerted efforts by media houses to cater for minority ethnic groups such as the Indian South African. With a population of just over a million, the Indian population is diverse in terms of language, religion and cultural practices. Indian South Africans are people of Indian descent mostly living in and around the city of Durban, making it 'the largest 'Indian' city outside India (Mukherji, Anahita: (http://articles.timesofindia.indiatimes.com/2011-07- 23/mumbai/29807173 _1_ durban-south-africa-uk). Many Indians in South Africa are descendants of migrants from colonial India. The Indian population in South Africa is a minority group that makes up just $2.5 \%$ of the total population of South Africa, that is, approximately 51770560 (www.southafrica.info). Although Indian languages are seldom spoken or understood by younger Indians, English-subtitled Bollywood films and television programmes remain popular among South African Indians. These are broadcast both by the South African Broadcasting Corporation's SABC 2 television channel for a few hours each week (Eastern Mosaic on Sundays), and by the DStv satellite television service, which carries Zee TV, B4U, NDTV and a Hindi-language Sony channel. In addition, Tamil-language channels, Sun TV and KTV, were introduced in 2004. In addition, the South African Broadcasting Corporation (SABC) also has an Indian-oriented radio service called Lotus FM. The Sunday Times has a supplement distributed in Indian areas (in KwaZulu-Natal (KZN), Gauteng and the Eastern Cape) called the Extra. The new forma covers issues around travel, health and wellness, weddings, youth, education and sport content and news Bollywood is a key feature. The format, says Extra editor Yasantha Naidoo, comes after market research revealed that generally readers were feeling disconnected from the Extra. Some felt it was too highbrow; some thought it was too sensational. Many felt they wanted more lifestyle-orientated content aimed at the Indian community. "What seemed to resonate with the readers [in the focus groups] was the good news and the success 
stories, as well as sport and education - these are very important in the Indian community," says Naidoo. "So our niche is that we're catering for the community's lifestyle aspirations" (Moodie, 2011).

\section{Research Methodology}

The approach used for this research is case study method. Welman and Kruger (1999) define the case study method as a "...limited number of units of analysis (often only one)...such as an individual, a group or an institution (which) are studied intensively." The Sunday Times Extra (a weekly supplement in The Sunday Times, a major national South African newspaper) serves as the primary unit of analysis for this paper. The primary unit of analysis is articles of women from The Sunday Times Extra over a 10 week period. Content analyses are typically performed on forms of human communication, including books, newspapers, films, television, art, music (Leedy and Ormrod, 2010). Jacob (2006) explains that to conduct a content analysis on any text, the text is coded or broken down into manageable categories on a variety of levels: word, word sentence, phrase, theme, visuals and then examined using one of content analysis's basic method, conceptual analysis or relational analysis. In terms of this paper, relational analysis is used as the focus extends beyond the frequency of certain words, phrases and themes but to the emergent meanings. In order to proceed with relational analysis, the categories need to be first selected. The newspaper issues and literature review served to identify these categories. Therefore the categories for analysis are: word sentence (language), visual imagery and the relationship to gender stereotypes.

\section{Analysis}

\subsection{Evolving Images of Women}

The media stereotypes girls to be raised as consumers of the future - domestic, caring and objects of beauty rather than producers. However, the Extra (24 May 2013) depicts an image of Ms Ela Gandhi, a political and social activist on the front page is an example of the varied images currently in the media. Ms Gandhi (the grand-daughter of Mahatma Gandhi) has a pair of running shoes in her hand and poses next to the bust of her grand-father. The caption highlights an annual event in Durban to commemorate the Salt March that Gandhi undertook in India in 1930. The Salt March is hosted by the city of Durban. Citizens, school children, politicians of all ethnic backgrounds walk from Gandhi's homestead in Inanda to the Durban Beachfront, stretching some 19 kilometers. These findings support Carter and Steiner's, (2004) assertion that, the "rigidity of such hierarchical feminine gendered identity has nevertheless begun to break down". There are varied images of women now available, some often progressive.

\subsection{A Deviant Case}

Unexpected generalizations in the course of data analysis lead one to seek out new deviant (unusual - unexpected) cases. Silverman (2006) notes that deviant cases go against the pattern identified. The Extra (30 June 2013) portrays a deviant image, under the mischievous sub-heading 'pimp my ride', of Durban businesswomen Shivani Pillay. She poses, seated on the bonnet of her graffiti-covered black and grey Volkswagen Golf 6 GTI. The 23 year old Durban businesswoman is a part-time criminology student and is portrayed as an energetic, assertive, successful career woman.

Another photograph in the Extra (7 July 2013) depicts table-tennis champ, Danisha Patel. She is one of 120 participants, heading for Russia to represent her country. The table tennis champ is also a $2^{\text {nd }}$ year BSc student at Johannesburg University. Representations of women have diversified, taking into account new roles and offering new identities. The cases identified above, seem to go against the grain of stereotype reporting of women and prove otherwise.

\subsection{Romance, sexuality and relationships}

The media thrives on the role that romance, love and drama play in a woman's life. During teenage years, young women's lives revolve around boyfriends and appearance. The romance eventually concludes in a marriage proposal and wedding. However, Milestone, and Meyer (2012) suggest that the media feed into the "conventional ideology of femininity" and "frames marriage and a family as life-goals". With the new look of the Extra, (9 June 2013) devotes a full page with colour photographs to a couple's dream wedding. Details of how the groom planned the proposal, the type of 
wedding ceremony, the menu at the wedding reception, the number of guests invited, the gifts given out at the wedding, the table settings and honeymoon details are accompanied by colour photographs.

In addition, there is a two page spread on Indian films from North India (Bollywood) and South India, lending to more romance, colour, dance and drama. The four photographs in The Extra (30 June 2013) in this section reflect romance, dance, drama and colour of Bollywood. The Indian film industry entertains billions of people around the globe (Raheja and Kothari, 2004). Its influences have also spread. Besides the song and dance, Bollywood has had an immense impact on the Indian fashion industry and has always been in the forefront to set trends (Chadha, 2009). Bollywood is by no means traditional and conventional with the modern iconic Bollywood screen goddess Aishwariya Rai shown in exotic poses.

\subsection{Women at the helm}

In essence, in order to appeal to a wider range of audiences, there has to be fair and diverse gender representation (Gallagher, 2004). The process begins in the newsrooms. This is evident in The Extra where the editor of the newspaper Yasantha Naidoo, is a woman. All four reporters are women, (Santham Pillay, Siphiliselwe Makhanya, Tashica Pillay and Doreen Premdev), so is their photographer (Jackie Clausen). The Extra seems to be fairly well balanced (if not titling towards a gendered newsroom. That could possibly be the reason women appear to be fairly represented in The Extra as suggested by Gallagher (2004).

\section{Conclusions and Recommendations}

The major findings of the investigation indicate that representations of the South African Indian woman has undoubtedly expanded, taking into account new roles and offering new identities, however certain stereotypical identities continue to prevail. In South Africa, ethnic women are producing their own representations, and there is increased visibility for them in the print media. Advocacy groups have assisted with increased and media representation of women. Stereotypical representation of the Indian South African has been challenged, changed and developed in the recent years. Based on the findings, the following recommendations are offered:

- The representation of ethnic women needs more exposure and should not focus on sexual attractiveness or stereotypical roles of women;

- Journalists need to guard against using photographs that sexualise women and detract attention away women's real identities.

The accurate representation of women is at its infancy stages. Change is painfully slow, especially amongst minority women. More needs to be done by media professionals to increase accurate reporting on women.

\section{References}

Ashford, L. and D Clifton. 2005. 2005 Women of our World: Population Reference Bureau. Washington: USAID. Available at: http://www.prb.org/pdf05/WomenOfOurWorld2005 Accessed 2 August 2008.

Brown, J. \& Campbell, K. (1986). Race and gender in music videos: The same beat but a different drummer. Journal of Communication, 36(1), 94_106.

Bunseelal, S. 2013. Dhanush rises to Bollywood occasion. Sunday Times Extra, 30 June: 13.

Carter, C. and Steinder, L. (Eds.). (2004). Mapping the contested terrain of media and gender research. In Carter, C. and Steinder, L. (Eds.). (2004). Critical Readings: Media and Gender. Berkshire: Open Press University.

Chadha, S. (2009). Bollywood Fashion - the Impact and Influence of Bollywood on Indian Fashion Industry (online). Available from: http://www.associatedcontect.com/pop_print.shtml?content. (Accessed 14 January 2009).

Coltrane, S. \& Messineo, M. (2000). The perpetuation of subtle prejudice: Race and gender imagery in 1990s television advertising. Sex Roles, 42, 363_389.

Courtney, A. \& S. Lockeretz. 1971. "A Woman's Place: An Analysis of the Roles Portrayed by Women in Magazine Advertisements." Journal of Marketing Research 8:92-5.

Entman, R. M. (1992). Blacks in the news: Television, modern racism and cultural change. Journalism Quarterly, 69, 341 _361.

Fourie, P.J. 2004. Media Studies: Institutions, Theories and Issues. Volume 1. Cape Town: Juta.

Gallagher, M. (2004). The Impact of Monitoring Media Images of Women. In Carter, C. and Steinder, L. (Eds.). (2004). Critical Readings: Media and Gender. Berkshire: Open Press University.

Hall, S. 1997. Representation: Cultural Representations and Signifying Practices. London: Sage Publications Ltd.

Holland, P. (2004). The Politics of the Smile. 'Soft news' and the sexualisation of the popular press. In Carter, C. and Steinder, L. (Eds.). (2004). Critical Readings: Media and Gender. Berkshire: Open Press University. 
Jacob, B. 2006. 'Content Analysis.' Available at: http://en.articlesgratuits.com/content-analysis-as-a-research-tool-id998.php (Accessed 3 July 2009).

Jeffres, L. (2000). Ethnicity and ethnic media use: A panel study. Communication Research, 27(4), 496-535.

Johnson, M. A., David, P., \& Huey, D. (2003). Beauty in brown: Skin color in Latina magazines. In D. I. Ríos \& A. N. Mohamed (Eds.), Brown and Black communication: Latino and African American conflict and convergence in mass media, (pp.159-174). Westport, CT: Praeger.

Leedy, P.D and J.E. Ormrod. 2010. Practical Research: Planning and Design. 9th edition. Boston: Pearson Education.

Makhanya, S. 2013. Distinctive wraps for every mood. Sunday Times Extra, 30 June: 16.

Mastro, D. E. \& Greenberg, B. S. (2000). The portrayal of racial minorities on prime time television. Journal of Broadcasting \& Electronic Media, 44, 690 703.

Milestone, K. \& Meyer, A. (2012). Gender and Popular Culture. Cambridge: Polity Press.

Moodie,G. 2011. Sunday Times Extra goes tabloid as it seeks a new niche. Available: www.bizcommunity.com/Article/196/90 157774.html. (Accessed 10 July 2013).

Morna, C.L. (2010). Global Media Monitoring Project 2010. (online). Available from http://www.genderlinkds.org.za (Accessed 5 June 2013)

Mukherji, Anahita (23 June 2011). "Durban largest 'Indian' city outside India". The Times of India. Retrieved 2011-11-30.

Nair, D. 2013. Nayanthrara convincing as Seetha. Sunday Times Extra, 30 June: 12.

O'Shaughnessy, M. and Stadler, J. (2006). Media and Society an Introduction. 3rd edition: Oxford University Press: South Melbourne, Victoria, Australia.

Parry, I. and B. Karam. 2001. 'Feminist Media Theory.' In: P.J. Fourie (ed) Media Studies: Institutions, Theories and Issues - Volume One. (304-28) Cape Town: Juta Education.

Peterson, R. C., Thurstone, L. L., Shuttlesworth, F. K., \& May, M. A. (1933). Motion pictures and the social attitudes of children. New York: The Macmillan company.

Phinney, J. S. (1990). Ethnic identity in adolescents and adults: Review of research. Psychological Bulletin, 108, $499-514$.

Pillay, T. 2013. Happy New Year! - and will you marry me? Sunday Times Extra, 9 June: 10.

Population Statistics of South Africa (online). 2012. Available from: http://www.southafrica.info/about/people/population.htm (accessed 8 July 2013)

Premdev, D. 2013.Table-tennis champ heads for Russia.Sunday Times Extra,7 July: 4.

Raheja, D. and Kothari, J. (2004). The Bollywood Saga. Indian Cinema. London: Aurum Press.

Renz, B. (2003). Theoretical foundation underlying minority group and media interaction. $112 \mathrm{In}$. Meiss, G. \& Tait, A. (Eds.), Ethnic media in America: Images, audiences and transforming forces, (pp. 3-25). Dubuque, IA: Kendall/Hunt Publishing Company.

Ricle Mayorga, P, "Ethnic Media and Identity Construction: Content Analysis of the Visual Portrayals of Women in Latina and Glamour Magazines" (2007). Communication Theses. Paper 22. http://digitalarchive.gsu.edu/communication_theses/22

Silverman, D. (2006). Interpreting Qualitative Data. New Delhi: Sage Publications

Stam, R. and Spence, L. 1983. Colonialism, Racism and Representation: An Introduction . In Stardom: The Industry of Desire, Christine Gledhill (ed.), Routledge, London, pp. 141-63

Subervi-Velez, F. (1986). The mass media and ethnic assimilation and pluralism: A review and research proposal with special focus on Hispanics. Communication Research, 13, 71-96.

Thomas, M. E. \& Treiber, L. A. (2000). Race, gender, and status: A content analysis of four advertisements in four popular magazines. Sociological Spectrum, 20, 357-371.

Tuchman, G. 1978. Hearth and Home: Images of Women and the Media. New York: Oxford University Press.

Turner, J. C. (1999). Some current issues in research on social identity and self-categorization theories. In N. Ellemers, R. Spears, \& B. Doosje (Eds.), Social Identity: Context, commitment, content. (pp. 6-34). Oxford, UK: Blackwell Publishers.

Wasserman, H. (2008). Media and the Construction of Identity. In Fourie, P.J. (Ed.). (2008). Media Studies. Volume 2. Policy, Managment and Media Representation. Cape Town: Juta.

Welman, J.C. and S.J. Kruger. 1999. Research Methodology for the Business and Administrative Sciences. Cape Town: Oxford University Press.

Williamson, J. 1978. Decoding Advertisements: Ideology and Meaning in Advertising. London: Marion Boyars.

Woodward, K. 2002. Understanding Identity. London: Arnold Publishers. 